\title{
Diffuse alveolar hemorrhage in childhood- onset systemic lupus erythematosus: a severe disease flare with serious outcome
}

Gabriela Blay ${ }^{1,2}$, Joaquim C. Rodrigues², Juliana C. O. Ferreira', Gabriela N. Leal' ${ }^{1}$, Natali W. Gormezano ${ }^{3}$, Glaucia V. Novak', Rosa M. R. Pereira ${ }^{3}$, Maria T. Terreri ${ }^{4}$, Claudia S. Magalhães ${ }^{5}$, Beatriz C. Molinari ${ }^{1}$, Ana P. Sakamoto ${ }^{4}$, Nadia E. Aikawa ${ }^{1,3}$, Lucia M. A. Campos ${ }^{1}$, Taciana A. P. Fernandes ${ }^{5}$, Gleice Clemente, Octavio A. B. Peracchi ${ }^{4}$, Vanessa Bugni ${ }^{4}$, Roberto Marini ${ }^{6}$, Silvana B. Sacchetti ${ }^{7}$, Luciana M. Carvalho ${ }^{8}$, Melissa M. Fraga ${ }^{9}$, Tânia C. M. Castro ${ }^{10}$, Valéria C. Ramos ${ }^{11}$, Eloisa Bonfá ${ }^{1}$, Clovis A. Silva ${ }^{1,2^{*}}$ (D) and Brazilian Childhood-onset Systemic Lupus Erythematosus Group

\begin{abstract}
Objective: To evaluate prevalence, clinical manifestations, laboratory abnormalities and treatment in a multicenter cohort study including 847 childhood-onset systemic lupus erythematosus (CSLE) patients with and without diffuse alveolar hemorrhage (DAH), as well as concomitant parameters of severity.

Methods: DAH was defined as the presence of at least three respiratory symptoms/signs associated with diffuse interstitial/alveolar infiltrates on chest $x$-ray or high-resolution computer tomography and sudden drop in hemoglobin levels. Statistical analysis was performed using Bonferroni correction $(p<0.0022)$.

Results: DAH was observed in 19/847 (2.2\%) CSLE patients. Cough/dyspnea/tachycardia/hypoxemia occurred in all CSLE patients with DAH. Concomitant parameters of severity observed were: mechanical ventilation in 14/19 (74\%), hemoptysis 12/19 (63\%), macrophage activation syndrome 2/19 (10\%) and death 9/19 (47\%). Further analysis of CSLE patients at DAH diagnosis compared to 76 CSLE control patients without DAH with same disease duration [3 (1-151) vs. $4(1-151)$ months, $p=0.335$, showed higher frequencies of constitutional involvement (74\% vs. 10\%, $p<0.0001)$, serositis (63\% vs. $6 \%, p<0.0001)$ and sepsis ( $53 \%$ vs. $9 \%, p<0.0001)$ in the DAH group. The median of disease activity score(SLEDAI-2 K) was significantly higher in CSLE patients with DAH [18 (5-40) vs. 6 (0-44), $p<0.0001$ ]. The frequencies of thrombocytopenia (53\% vs. 12\%, $p<0.0001$ ), intravenous methylprednisolone ( $95 \%$ vs. $16 \%, p<0.0001)$ and intravenous cyclophosphamide ( $47 \%$ vs. $8 \%, p<0.0001)$ were also significantly higher in DAH patients.

Conclusions: This was the first study to demonstrate that DAH, although not a disease activity score descriptor, occurred in the context of significant moderate/severe cSLE flare. Importantly, we identified that this condition was associated with serious disease flare complicated by sepsis with high mortality rate.
\end{abstract}

Keywords: Diffuse alveolar hemorrhage, Childhood, Systemic lupus erythematosus, Multicenter study

\footnotetext{
* Correspondence: clovisaasilva@gmail.com

'Pediatric Rheumatology Unit, Children's Institute, Faculdade de Medicina da

Universidade de São Paulo (FMUSP), Av. Dr. Eneas Carvalho Aguiar, 647 -

Cerqueira César, São Paulo, SP 05403-000, Brazil

${ }^{2}$ Pediatric Pulmonology Unit, Children's Institute, FMUSP, Av. Dr. Eneas

Carvalho Aguiar, 647 - Cerqueira César, São Paulo, SP 05403-000, Brazil

Full list of author information is available at the end of the article
}

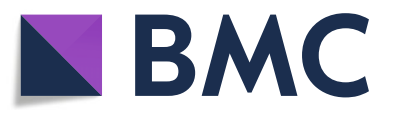

(c) The Author(s). 2018 Open Access This article is distributed under the terms of the Creative Commons Attribution 4.0 International License (http://creativecommons.org/licenses/by/4.0/), which permits unrestricted use, distribution, and reproduction in any medium, provided you give appropriate credit to the original author(s) and the source, provide a link to the Creative Commons license, and indicate if changes were made. The Creative Commons Public Domain Dedication waiver (http://creativecommons.org/publicdomain/zero/1.0/) applies to the data made available in this article, unless otherwise stated. 


\section{Introduction}

Systemic lupus erythematosus (SLE) is a multisystemic autoimmune disease characterized by the involvement of several organs and systems [1-3]. Pleuropulmonary manifestations were described as initial feature from 17 to $42 \%$ childhood-onset SLE (cSLE) patients, particularly mild to moderate pleuritis [1, 3-5]. These respiratory complications may be classified as acute or chronic [6].

Of note, diffuse alveolar hemorrhage (DAH) is an acute, rare and life-threatening pulmonary manifestation characterized by sudden onset of respiratory symptoms, such as dyspnea; hypoxemia; hemoptysis; tachycardia and/or cough; associated with new lung infiltrates on chest $\mathrm{x}$-ray (CXR) or high-resolution computer tomography (HRCT); and sudden drop in serum hemoglobin levels $[7,8]$.

Data of DAH in cSLE patients are limited due to the small representation of this complication in previous case series or the focus on the comparison to adult SLE, precluding an accurate analysis of associated factors and outcomes in patients with and without this severe complication [4, 7-15].

Therefore, the objective of the present multicenter cohort study was to assess the prevalence and the possible DAH association with demographic, clinical manifestations, laboratory abnormalities, disease activity score, treatments and outcomes in a large cSLE population.

\section{Methods}

This was a retrospective multicenter cohort study including 1017 patients followed in 10 Pediatric Rheumatology tertiary referral services in São Paulo state, Brazil. One hundred and sixty five patients were excluded due to: incomplete medical charts $(n=96)$, undifferentiated connective tissue disorder with 3 or fewer American College of Rheumatology (ACR) criteria $(n=43)$, isolated cutaneous lupus erythematosus $(n=11)$, neonatal lupus erythematosus $(n=8)$, drug-induced lupus $(n=5)$ and mixed connective tissue disease $(n=2)$. Therefore, this study group comprised 852 cSLE patients. All of them fulfilled the ACR criteria for SLE [16], with disease onset before the age of 18 [17].

An investigator meeting was held for protocol training according to the clinical parameters definitions and disease activity tool scoring, as previously reported [3, 18]. Patient's medical charts were systematically reviewed according to demographic data, clinical characteristics, DAH features, laboratorial abnormalities, therapies and outcomes.

DAH was defined as the presence of at least three respiratory symptoms and signs (dyspnea, hypoxemia, hemoptysis, tachycardia and/or cough) associated with diffuse interstitial and/or alveolar infiltrates on CXR or
HRCT, and sudden drop in hemoglobin level at least of $1.5 \mathrm{~g} / \mathrm{dL}$ [7, 10, 11]. Bronchoalveolar lavage with hemosiderin-laden macrophages evidence was also recorded [14]. Patients were divided in two groups with similar disease duration: cSLE patients with DAH (assessed at DAH diagnosis) and cSLE patients without $\mathrm{DAH}$ (assessed at last visit).

Descriptors and definitions of SLE Disease Activity Index 2000 (SLEDAI-2 K) score were used to characterize disease parameters and to calculate disease activity score [19]. Custom definitions were defined as previously reported [3, 18]. Neuropsychiatric lupus included 19 syndromes according to ACR classification criteria [20]. Antiphospholipid syndrome was diagnosed taking into account the presence of arterial and/or venous thrombosis concomitant to high titers of antiphospholipid antibodies [21]. Macrophage activation syndrome was diagnosed considering the preliminary cSLE diagnostic guidelines, requiring the presence of at least one clinical plus two laboratorial criteria [22].

Laboratorial assessment included complete blood cell count and urine test. Anti-double-stranded DNA (anti-dsDNA), IgG and IgM anticardiolipin antibodies $(\mathrm{aCL})$ were carried out at each center and the cutoff values were considered valid. Lupus anticoagulant was detected according to the guidelines of the International Society on Thrombosis and Hemostasis [23].

Drug treatment data (prednisone, intravenous methylprednisolone, chloroquine diphosphate, hydroxychloroquine sulfate, methotrexate, azathioprine, cyclosporine, mycophenolate mofetil, intravenous cyclophosphamide and intravenous gammaglobulin) were also recorded.

\section{Statistical analysis}

Results were presented as an absolute number (frequency) for categorical variables and median (range) or mean \pm standard deviation (SD) for continuous variables. Categorical variables comparisons were assessed by Pearson $X$-Square or Fisher's exact test. Continuous variables from cSLE patients with and without DAH were compared by Mann-Whitney test or $t$ test as appropriate. Statistical analysis was performed using Bonferroni correction $(p<0.0022)$.

\section{Results}

DAH was observed in 19/847 (2.2\%) cSLE patients. Cough, dyspnea, tachycardia and hypoxemia occurred in all 19 cSLE patients with DAH; hemoptysis in 12/19 and endotracheal tube bleeding in 14/19. New infiltrates on CXR or HRCT and hemoglobin drop at least of $1.5 \mathrm{~g} / \mathrm{dL}$ were evidenced in all cSLE patients with DAH (Table 1). Bronchoalveolar lavage was performed in two cSLE patients and hemosiderin-laden macrophage was observed in both of them. 
Table 1 Demographic, clinical manifestations and imaging in 19 childhood-onset systemic lupus erythematosus (cSLE) patients with diffuse alveolar hemorrhage

\begin{tabular}{|c|c|c|c|c|c|c|c|c|}
\hline Patient & Disease duration, Months & Cough & Dyspnoea & Tachycardia & Hypoxemia & $\begin{array}{l}\text { Hemoptysis/bleeding in } \\
\text { endotracheal tube }\end{array}$ & $\begin{array}{l}\text { New Infiltrates } \\
\text { CXR or HRCT }\end{array}$ & Drop Hbg/dL \\
\hline 1 & 60 & + & + & + & + & $+1+$ & + & 1.8 \\
\hline 2 & 151 & + & + & + & + & $+/+$ & + & 1.5 \\
\hline 3 & 5 & + & + & + & + & $+/+$ & + & 2.0 \\
\hline 4 & 0 & + & + & + & + & $+/+$ & + & 1.6 \\
\hline 5 & 33 & + & + & + & + & $+/+$ & + & 1.9 \\
\hline 6 & 0 & + & + & + & + & $+1+$ & + & 2.7 \\
\hline 7 & 3 & + & + & + & + & $+/+$ & + & 1.7 \\
\hline 8 & 90 & + & + & + & + & $+1-$ & + & 2.5 \\
\hline 9 & 42 & + & + & + & + & $+/+$ & + & 4.5 \\
\hline 10 & 4 & + & + & + & + & $+1+$ & + & 3.0 \\
\hline 11 & 0 & + & + & + & + & $-/-$ & + & 3.2 \\
\hline 12 & 47 & + & + & + & + & $-1+$ & + & 1.5 \\
\hline 13 & 5 & + & + & + & + & $-1+$ & + & 1.5 \\
\hline 14 & 0 & + & + & + & + & $+/-$ & + & 2.0 \\
\hline 15 & 0 & + & + & + & + & $-1+$ & + & 7.0 \\
\hline 16 & 0 & + & + & + & + & $-1-$ & + & 2.0 \\
\hline 17 & 3 & + & + & + & + & $-1+$ & + & 2.0 \\
\hline 18 & 1 & + & + & + & + & $-1-$ & + & 1.7 \\
\hline 19 & 0 & + & + & + & + & $+/+$ & + & 8.0 \\
\hline
\end{tabular}

CXR Chest x-ray, HRCT High resolution computer tomography, Hb Hemoglobulin, ND Not done

Regarding outcomes, hospitalization in pediatric intensive care unit occurred in $17 / 19$ cSLE patients with DAH and mechanical ventilation in 14/19. DAH associated with sepsis was observed in 10/19 cSLE patients. Concomitant macrophage activation syndrome was evidenced in 2/19 patients. Death was observed in 9/19 cSLE patients. The median duration between DAH onset and death was 2 days (0.5-25). Blood erythrocyte transfusion and broad-spectrum antibiotics were administered in all cSLE patients with DAH. Intravenous methylprednisolone pulse therapy was used in 18/19 cSLE and intravenous cyclophosphamide in 9/19 (Table 2). None of them had recurrence of DAH.

Further comparison between cSLE patients with DAH compared to 76 cSLE control patients without DAH with same disease duration [3 (1-151) vs. 4 (1-151) months, $p=0.335]$, showed significantly higher frequencies of constitutional involvement ( $74 \%$ vs. $10 \%$, $p<0.0001)$, serositis $(63 \%$ vs. $6 \%, \mathrm{p}<0.0001)$ and sepsis $(53 \%$ vs. $9 \%, p<0.0001)$ in the former group. The median of SLEDAI-2 $\mathrm{K}$ was significantly higher in cSLE patients with DAH compared to cSLE patients without this complication $[18(5-40)$ vs. 6 $(0-44), \quad p<0.0001]$. Frequencies of nephritis and neuropsychiatric involvements were similar in both groups $(p>0.0022)$ (Table 3$)$.
The frequencies of thrombocytopenia (53\% vs. $12 \%$, $p<0.0001)$, intravenous methylprednisolone $(95 \%$ vs. $16 \%, p<0.0001)$ and intravenous cyclophosphamide ( $47 \%$ vs. $8 \%, p<0.0001)$ were also significantly higher in the former group. The median of prednisone dose was higher in cSLE patients with DAH compared to those without DAH [1.4 (0.3-2) vs. $0.5(0.03-3) \mathrm{mg} / \mathrm{Kg}$, $p<0.0001$ ] (Table 4).

\section{Discussion}

This is the largest study to evaluate $\mathrm{DAH}$, a rare and acute life-threatening pulmonary manifestation, in cSLE population.

The multicenter study design with a large cohort of children and adolescents patients allowed a more precise assessment of this rare and severe cSLE respiratory complication. An investigator meeting was also taken in place to standardize the protocol study in all centers. However, the limitation was the retrospective design with potential missing data.

The prevalence of DAH in cSLE patients in the present study was similar to other reports, varying from 2 to $5 \%[6,7,24]$. Diagnosis of this condition included the typical respiratory symptoms and signs, drop in hemoglobin levels and the radiographic evidence of pulmonary infiltrates, as well as the assessment of 
Table 2 Outcomes and immunosuppressive treatment in 19 childhood-onset systemic lupus erythematosus (cSLE) patients with diffuse alveolar hemorrhage

\begin{tabular}{|c|c|c|c|c|c|c|c|}
\hline Patient & $\mathrm{ICU}$ & Mechanical ventilation & Sepsis & MAS & Death & $\begin{array}{l}\text { IV methylprednisolone } \\
\text { pulse therapy }\end{array}$ & IV cyclophosphamide \\
\hline 1 & + & + & + & - & + & + & - \\
\hline 2 & + & + & + & - & - & + & + \\
\hline 3 & + & + & + & - & + & + & - \\
\hline 4 & + & + & + & - & - & + & + \\
\hline 5 & + & + & - & - & + & + & - \\
\hline 6 & + & + & - & - & - & + & + \\
\hline 7 & + & + & + & - & + & + & + \\
\hline 8 & + & - & + & - & + & + & + \\
\hline 9 & + & + & - & - & + & + & - \\
\hline 10 & + & + & - & - & - & + & + \\
\hline 11 & + & - & - & - & - & + & - \\
\hline 12 & + & + & - & + & + & + & - \\
\hline 13 & + & + & - & - & + & - & - \\
\hline 14 & + & - & + & - & - & + & + \\
\hline 15 & + & + & + & + & - & + & + \\
\hline 16 & - & - & + & - & - & + & - \\
\hline 17 & + & + & + & - & - & + & + \\
\hline 18 & - & - & - & - & - & + & - \\
\hline 19 & + & + & - & - & + & + & - \\
\hline
\end{tabular}

ICU Intensive care unit, MAS Macrophage activation syndrome, IV Intravenous

Table 3 Demographic data, clinical manifestations and disease activity score in childhood-onset systemic lupus erythematosus (cSLE) patients according to the presence of diffuse alveolar hemorrhage (DAH)

\begin{tabular}{|c|c|c|c|}
\hline Variables & $\begin{array}{l}\text { With DAH (at diagnosis) } \\
(n=19)\end{array}$ & $\begin{array}{l}\text { Without DAH (at last visit) } \\
(n=76)\end{array}$ & $P$ \\
\hline \multicolumn{4}{|l|}{ Demographic data } \\
\hline Female gender & $14(74)$ & $66(87)$ & 0.172 \\
\hline Disease duration, months & $3(1-151)$ & $4(1-151)$ & 0.335 \\
\hline Current age, years & $13(9-18)$ & $13(3-23)$ & 0.889 \\
\hline \multicolumn{4}{|l|}{ Current clinical manifestations } \\
\hline Constitutional & $14(74)$ & $8(10)$ & $<0.0001^{*}$ \\
\hline Mucocutaneous & $9(47)$ & $31(41)$ & 0.614 \\
\hline Musculoskeletal & $5(26)$ & $8(10)$ & 0.127 \\
\hline Serositis & $12(63)$ & $5(6)$ & $<0.0001^{*}$ \\
\hline Neuropsychiatric & $4(21)$ & $11(14)$ & 0.491 \\
\hline Nephritis & $16(84)$ & $42(55)$ & 0.033 \\
\hline Current autoimmune thrombosis (APS), $n=90$ & $0 / 16(0)$ & $1 / 74(1)$ & 1.000 \\
\hline Sepsis & $10(53)$ & $7(9)$ & $<0.0001^{*}$ \\
\hline Macrophage activation syndrome & $2(10)$ & $2(3)$ & 0.113 \\
\hline Death, $n=94$ & $9(47)$ & 15/75 (20) & 0.020 \\
\hline \multicolumn{4}{|l|}{ Current disease activity } \\
\hline SLEDAI- $2 \mathrm{~K}, n=82$ & $18(5-40)$ & $6(0-44)$ & $<0.0001^{*}$ \\
\hline
\end{tabular}

*P-value according to Bonferroni correction for multiple comparisons $(p<0.0022)$. Results are presented in $n(\%)$ and median (range), APS Antiphospholipid syndrome, SLEDAI-2 K Systemic Lupus Erythematosus Disease Activity Index 2000 
Table 4 Current laboratory tests and drug therapy of childhood-onset systemic lupus erythematosus (cSLE) according to the presence of diffuse alveolar hemorrhage (DAH)

\begin{tabular}{|c|c|c|c|}
\hline Variables & $\begin{array}{l}\text { With DAH (at diagnosis) } \\
(n=19)\end{array}$ & $\begin{array}{l}\text { Without DAH (at last visit) } \\
(n=76)\end{array}$ & $P$ \\
\hline \multicolumn{4}{|l|}{ Current laboratory exams } \\
\hline Autoimmune hemolytic anemia & $5(26)$ & $8(10)$ & 0.127 \\
\hline Thrombocytopenia, $<150,000 / \mathrm{mm}^{3}, n=93$ & $10(52)$ & 9/74 (12) & $<0.0001^{*}$ \\
\hline Anti-ds-DNA, $n=75$ & $8 / 13(61)$ & $30 / 62(48)$ & 0.544 \\
\hline \multicolumn{4}{|l|}{ Drug therapy } \\
\hline Prednisone current dose, $\mathrm{mg} / \mathrm{Kg}, n=82$ & $1.4(0.3-2)$ & $0.5(0.03-3)$ & $<0.0001^{*}$ \\
\hline Intravenous methylprednisolone & $18(95)$ & $12(15)$ & $<0.0001^{*}$ \\
\hline Antimalarial drugs & $14(74)$ & $41(54)$ & 0.193 \\
\hline Azathioprine & $2(10)$ & $16(21)$ & 0.513 \\
\hline Mycophenolate mofetil & $1(5)$ & $5(6)$ & 1.000 \\
\hline Intravenous cyclophosphamide & $9(47)$ & $6(8)$ & $<0.0001^{*}$ \\
\hline
\end{tabular}

stranded DNA antibodies

hypoxemia due to acute respiratory distress [7]. In addition, in two of our cSLE patients the presence of haemosiderin-laden macrophages in the absence of bloody fluid suggested recent bleeding [6], analyzed by the bronchoalveolar lavage.

We demonstrated that $\mathrm{DAH}$, although not a disease activity score descriptor of SLEDAI-2 K [19], was associated with high moderate or severe disease activity scores, particularly thrombocytopenia, serositis and constitutional involvement. In contrast to previous reports DAH was not associated with lupus nephritis [13].

Of note, we identified that DAH was a severe manifestation requiring pediatric intensive care unit hospitalization and mechanical ventilation for the vast majority of our patients. We extended previous observation of high frequency of severe infection in adults/cSLE patients with DAH [7], thus demonstrating the catastrophic nature of DAH, since more than half of cSLE patients developed concomitant sepsis.

Reinforcing this finding of poor outcome, $10 \%$ of the cSLE patients were diagnosed with concomitant macrophage activation syndrome. In fact, this is a rare condition characterized by an excessive activation and proliferation of $\mathrm{T}$ lymphocytes and macrophages with massive hypersecretion of proinflammatory cytokines, and may induce severe hemorraghae [25, 26].

We observed a high mortality rate in cSLE patients with $\mathrm{DAH}$, as also observed in other studies [6, 10, 11]. This unfavorable outcome revealed that sepsis and macrophage activation syndrome may have contributed to the death of more than half of the patients.

Early detection of this severe pulmonary complication, prompt immunosuppressive agents treatment $[9,15,27]$, empirical antibiotics and mechanical ventilation are therefore essential to improve cSLE outcome $[6,7]$.

\section{Conclusion}

This was the first study to demonstrate that DAH, although not a disease activity score descriptor, occurs in the context of significant moderate/severe cSLE flare. Importantly, we identified that this condition is associated with serious disease flare complicated by sepsis and high mortality rate.

\section{Acknowledgements}

Our gratitude to Ulysses Doria-Filho for the statistical analysis. The authors thank the following Pediatric Rheumatology Divisions and colleagues for including their patients: Children's Institute, FMUSP (Marco F. Silva, Mariana Ferriani, Roberta C. Gomes, Victor L. Marques, Gabriella E. Lube, Sandra R. M. Lopes, Glaucia V. Novak, Beatriz C. Molinari, Clarissa C. Valões, Verena Balbi, João D. Montoni, Laila P. Coelho, Luciana S. Henriques, Pedro Anuardo, Monica Verdier, Juliana B. Brunelli, Adriana A. Jesus, Antonio C. Pastorino, Heloisa H. Marques, Andrea Watanabe, Benita G. Schvartsman, Maria H. Vaisbich, Werther B. Carvalho, Magda Carneiro-Sampaio, Vicente OdoneFilho); Division of Rheumatology, FMUSP (Juliane A. Paupitz, Glauce L. Lima, Ana Paula L. Assad); UNIFESP (Maria O. E. Hilário, Andreia S. Lopes, Aline Alencar, Daniela P. Piotto, Giampaolo Faquin); UNESP (Priscila R. Aoki, Juliana O. Sato, Silvana P. Cardin); Irmandade da Santa Casa de Misericórdia de São Paulo (Andressa Guariento, Eunice Okuda, Maria Carolina dos Santos); UNICAMP (Maraísa Centeville, Renata Barbosa, Simone Appenzeller); Ribeirão Preto Medical School, FMUSP (Paola P. Kahwage, Gecilmara Pileggi, Francisco Hugo Gomes, Virginia Ferriani), Hospital Infantil Darcy Vargas (Jonatas Libório, Cássia Barbosa, Luciana T. P. Paulo); Hospital Municipal Infantil Menino Jesus (Simone Lotufo)

\section{Funding}

This study was supported by grants from Conselho Nacional de Desenvolvimento Científico e Tecnológico (CNPq 301805/2013-0 to RMRP, $303752 / 2015-7$ to MTT, 301479/2015-1 to CSM, 305068/2014-8 to EB and $303422 / 2015-7$ to CAS), Federico Foundation (to EB, RMRP and CAS) and by Núcleo de Apoio à Pesquisa "Saúde da Criança e do Adolescente" da USP (NAP-CriAd) to CAS.

Availability of data and materials Not applicable. 


\section{Authors' contributions}

All authors analyzed and interpreted the patient data regarding autoimmune hepatitis in childhood onset systemic lupus erythematosus. GB, EB and CAS were the major contributor in writing the manuscript. All authors read and approved the final manuscript.

\section{Ethics approval and consent to participate}

This study was approved by our Ethics Committee.

\section{Consent for publication}

Not applicable.

\section{Competing interests}

The authors declare that they have no competing interests.

\section{Publisher's Note}

Springer Nature remains neutral with regard to jurisdictional claims in published maps and institutional affiliations.

\section{Author details}

'Pediatric Rheumatology Unit, Children's Institute, Faculdade de Medicina da Universidade de São Paulo (FMUSP), Av. Dr. Eneas Carvalho Aguiar, 647 Cerqueira César, São Paulo, SP 05403-000, Brazil. ${ }^{2}$ Pediatric Pulmonology Unit, Children's Institute, FMUSP, Av. Dr. Eneas Carvalho Aguiar, 647 - Cerqueira César, São Paulo, SP 05403-000, Brazil. ${ }^{3}$ Division of Rheumatology, FMUSP, Sao Paulo, Brazil. ${ }^{4}$ Pediatric Rheumatology Unit, Universidade Federal de São Paulo, Sao Paulo, Brazil. ${ }^{5}$ São Paulo State University (UNESP), Faculdade de Medicina de Botucatu, Sao Paulo, Brazil. 'São Paulo State University of Campinas (UNICAMP), Sao Paulo, Brazil. " Irmandade da Santa Casa de Misericórdia de São Paulo, Sao Paulo, Brazil. ${ }^{8}$ Ribeirão Preto Medical School University of São Paulo, Sao Paulo, Brazil. ${ }^{9}$ Hospital Darcy Vargas, Sao Paulo, Brazil. ${ }^{10}$ Hospital Menino Jesus, Sao Paulo, Brazil. ${ }^{11}$ Pontifical Catholic University of Sorocaba, Sao Paulo, Brazil.

\section{Received: 13 September 2018 Accepted: 16 October 2018}

Published online: 23 November 2018

\section{References}

1. Silva CA. Childhood-onset systemic lupus erythematosus: early disease manifestations that the paediatrician must know. Expert Rev Clin Immunol. 2016;12:907-10

2. Silva CA, Aikawa NE, Pereira RM, Campos LM. Management considerations for childhood-onset systemic lupus erythematosus patients and implications on therapy. Expert Rev Clin Immunol. 2016;12:301-13.

3. Gomes RC, Silva MF, Kozu K, Bonfá E, Pereira RM, Terreri MT, et al. Features of 847 childhood-onset systemic lupus Erythematousus patients in three age groups at diagnosis: a Brazilian multicenter study. Arthritis Care Res (Hoboken). 2016;68:1736-41.

4. Veiga CS, Coutinho DS, Nakaie CM, Campos LM, Suzuki L, Cunha MT, et al. Subclinical pulmonary abnormalities in childhood-onset systemic lupus erythematosus patients. Lupus. 2016;25:645-51.

5. Bader-Meunier B, Armengaud JB, Haddad E, Salomon R, Deschênes G, KonéPaut I, et al. Initial presentation of childhood-onset systemic lupus erythematosus: a French multicenter study. J Pediatr. 2005;146:648-53

6. Richardson AE, Warrier K, Vyas H. Respiratory complications of the rheumatological diseases in childhood. Arch Dis Child. 2016;101:752-8.

7. Araujo DB, Borba EF, Silva CA, Campos LM, Pereira RM, Bonfa E, et al. Alveolar hemorrhage: distinct features of juvenile and adult onset systemic lupus erythematosus. Lupus. 2012;21:872-7.

8. Singla S, Canter DL, Vece TJ, Muscal E, DeGuzman M. Diffuse Alveolar Hemorrhage as a Manifestation of Childhood-Onset Systemic Lupus Erythematosus. Hosp Pediatr. 2016;6:496-500.

9. Godfrey S. Pulmonary hemorrhage/hemoptysis in children. Pediat Pulmonol. 2004;37:476-84.

10. Liu MF, Lee JH, Weng TH, Lee YY. Clinical experience of 13 cases with severe pulmonary hemorrhage in systemic lupus erythematosus with active nephritis. Scand J Rheumatol. 1998:27:291-5.

11. Chang MY, Fang JT, Chen YC, Huang CC. Diffuse alveolar hemorrhage in systemic lupus erythematosus: a single center retrospective study in Taiwan. Ren Fail. 2002;24:791-802.
12. Koh WH, Thumboo J, Boey ML. Pulmonary haemorrhage in oriental patients with systemic lupus erythematosus. Lupus. 1997:6:713-6.

13. Shen $M$, Zeng $X$, Tian X, Zhang F, Zeng X, Zhang X, et al. Diffuse alveolar hemorrhage in systemic lupus erythematosus: a retrospective study in China. Lupus. 2010;19:1326-30.

14. Martinez-Martinez MU, Sturbaum AK, Alcocer-Varela J, Merayo-Chalico J, Gómez-Martin D, Gómez-Bañuelos Jde J, et al. Factors associated with mortality and infections in patients with systemic lupus erythematosus with diffuse alveolar hemorrhage. J Rheumatol. 2014;41:1656-61.

15. Kimura D, Shah S, Briceno-Medina M, Sathanandam S, Haberman B, Zhang J, et al. Management of massive diffuse alveolar hemorrhage in a child with systemic lupus erythematosus. J Intensive Care. 2015;7(3):10.

16. Hochberg MC. Updating the American College of Rheumatology revised criteria for the classification of systemic lupus erhytematosus. Arthrits Rheum. 1997:40:1725.

17. Silva CA, Avcin T, Brunner HI. Taxonomy for systemic lupus erythematosus with onset before adulthood. Arthritis Care Res (Hoboken). 2012;64:1787-93.

18. Marques VL, Gormezano NW, Bonfá E, Aikawa NE, Terreri MT, Pereira RM, et al. Pancreatitis subtypes survey in 852 childhood-onset systemic lupus erythematosus patients. J Pediatr Gastroenterol Nutr. 2016;62:328-34.

19. Gladman DD, Ibañez D, Urowitz MB. Systemic lupus erythematosus disease activity index 2000. J Rheumatol. 2002;29:288-91.

20. American College of Rheumatology Ad Hoc committee on neuropsychiatric Lupus Syndromes. The American College of Rheumatology nomenclature and case definitions for neuropsychiatric lupus syndromes. Arthritis Rheum. 1999:42:599-608.

21. Avcin T, Cimaz R, Rozman B. The Ped-APS Registry: the antiphospholipid syndrome in childhood. Lupus. 2009;18:894-9.

22. Parodi A, Davì S, Pringe AB, Pistorio A, Ruperto N, Magni-Manzoni S, et al. Lupus Working Group of the Paediatric Rheumatology European Society. A macrophage activation syndrome in juvenile systemic lupus erythematosus: a multinational multicenter study of thirty-eight patients. Arthritis Rheum. 2009:60:3388-99.

23. Brandt JT, Triplett DA, Alving B, Scharrer I. Criteria for the diagnosis of lupus anticoagulants: an update. On behalf of the subcommittee on lupus anticoagulant/antiphospholipid antibody of the scientific and standardisation committee of the ISTH. Thromb Haemost. 1995:74:1185-90.

24. Fatemi A, Matinfar M, Saber M, Smiley A. The association between initial manifestations of childhood-onset systemic lupus erythematosus and the survival. Int J Rheum Dis. 2016;19:974-80. in press.

25. Gormezano NW, Otsuzi Cl, Barros DL, da Silva MA, Pereira RM, Campos LM, et al. Macrophage activation syndrome: A severe and frequent manifestation of acute pancreatitis in 362 childhood-onset compared to 1830 adult-onset systemic lupus erythematosus patients. Semin Arthritis Rheum. 2016;45:706-10.

26. Aikawa NE, Carvalho JF, Bonfá E, Lotito AP, Silva CA. Macrophage activation syndrome associated with etanercept in a child with systemic onset juvenile idiopathic arthritis. Isr Med Assoc J. 2009:11:635-6.

27. Klumb EM, Silva CA, Lanna CC, Sato El, Borba EF, Brenol JC, et al. Consensus of the Brazilian Society of Rheumatology for the diagnosis, management and treatment of lupus nephritis. Rev Bras Reumatol. 2015;55:1-21.
Ready to submit your research? Choose BMC and benefit from:

- fast, convenient online submission

- thorough peer review by experienced researchers in your field

- rapid publication on acceptance

- support for research data, including large and complex data types

- gold Open Access which fosters wider collaboration and increased citations

- maximum visibility for your research: over $100 \mathrm{M}$ website views per year

At $\mathrm{BMC}$, research is always in progress.

Learn more biomedcentral.com/submissions 